\title{
Leitura e interseccionalidade: \\ a experiência do Leia Mulheres Marechal Deodoro
}

\author{
SILVA, Edilma José da ${ }^{1}$ \\ SANTOS, Elaine Cristina Rapôso dos²
}

\section{RESUMO}

Este artigo relata a experiência do clube de leitura Leia Mulheres Marechal Deodoro, como proposta pedagógica voltada para a formação de leitoras e leitores no contexto da educação básica. A partir da perspectiva metodológica da pedagogia engajada, o clube constitui-se como uma "comunidade de aprendizado", conforme apresentada por Hooks (2017). Dessa forma, responde concretamente aos desafios de formar leitoras e leitores no contexto escolar, respeitando a voz, a experiência de cada integrante do clube e buscando o desenvolvimento da sua autonomia. A partir da discussão de textos de autoria feminina, o clube aborda questões de gênero, raça e classe, numa perspectiva interseccional (AKOTIRENE, 2019). Essa abordagem implica a necessidade de discutir a noção de cânone, Reis (1992), e Wollf (1985), bem como a de lugar de fala, Ribeiro (2017). Como projeto de ensino institucionalizado, ele funciona desde julho de 2017, no Instituto Federal de Alagoas, Campus Marechal Deodoro.

Interseccionalidade. Formação de leitoras/es. Leia mulheres.

\section{Reading and intersectionality: the experience of Leia Mulheres Marechal Deodoro}

\section{ABSTRACT}

This article reports the experience of the "Leia Mulheres Marechal Deodoro" Reading Club, as a pedagogical proposal aimed at training readers in the context of basic education. From the methodological perspective of engaged pedagogy, the club is constituted as a "learning community", as presented by Hooks (2017). This way, it responds concretely to the challenges of training readers in the school context, respecting each member of the club's voice and experience and seeking the development of their autonomy. From the discussion of female authorship texts, the club addresses issues of gender, race and class, in an intersectional

\footnotetext{
${ }_{1}^{1}$ Mestra em Geografia pelo Programa de Pós-graduação em Geografia da Universidade Federal de Sergipe - PPGEO/UFS. E-mail: edilma.geoufal@gmail.com. Lattes: http://lattes.cnpq.br/5264663076064041. ORCID: http://orcid.org/0000-0002-1955-9619. 2 Doutora em Estudos Literários pelo Programa de Pós-Graduação em Letras e Linguística da Universidade Federal de Alagoas - PPGLL/UFAL. Professora do Instituto Federal de Alagoas IFAL, campus Marechal Deodoro. E-mail: elaineraposo.ifal@gmail.com. Lattes: http://lattes.cnpq.br/0758592442310125. ORCID: http://orcid.org/0000-0003-1952-4384.
}

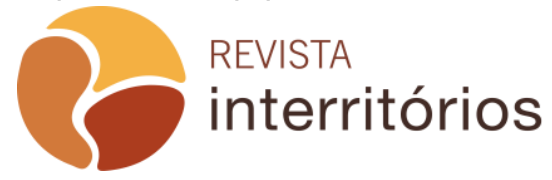


perspective (AKOTIRENE, 2019). This approach implies the need to discuss the notion of canon, Reis (1992) and Wollf (1985), as well as the place of speech, Ribeiro (2017). It is an institutionalized teaching project that has been operating at the Federal Institute of Alagoas, Campus Marechal Deodoro, since July 2017.

Intersectionality. Training of readers. Read women.

\section{Lectura e interseccionalidad: la experiencia de Leia Mulheres Marshal Deodoro}

\section{RESUMEN}

Este artículo informa sobre la experiencia del club de lectura Leia Mulheres Marechal Deodoro, como una propuesta pedagógica dirigida a capacitar a los lectores en el contexto de la educación básica. Desde la perspectiva metodológica de la pedagogía comprometida, el club se constituye como una "comunidad de aprendizaje", según lo presentado por Hooks (2017). Por lo tanto, responde concretamente a los desafíos de capacitar a los lectores en el contexto escolar, respetando la voz, la experiencia de cada miembro del club y buscando el desarrollo de su autonomía. A partir de la discusión de textos escritos por mujeres, el club aborda cuestiones de género, raza y clase, en una perspectiva interseccional (AKOTIRENE, 2019). Este enfoque implica la necesidad de discutir la noción de canon, Reis (1992) y Wollf (1985), así como el lugar de expresión, Ribeiro (2017). Como un proyecto de enseñanza institucionalizado, ha estado operando desde julio de 2017, en el Instituto Federal de Alagoas, Campus Marechal Deodoro.

Interseccionalidad. Formación de lectores / es. Lee mujeres.

\section{Lettura e intersezionalità: l'esperienza del maresciallo Deodoro Leia Mulheres}

\section{SINTESE}

Questo articolo riporta l'esperienza del club di lettura Leia Mulheres Marechal Deodoro, come una proposta pedagogica volta a formare i lettori nel contesto dell'istruzione di base. Dal punto di vista metodologico della pedagogia impegnata, il club è costituito come una "comunità di apprendimento", come presentato da Hooks (2017). Quindi, risponde concretamente alle sfide della formazione dei lettori nel contesto scolastico, rispettando la voce, l'esperienza di ciascun membro del club e cercando lo sviluppo della loro autonomia. Dalla discussione di testi scritti da donne, il club affronta questioni di genere, razza e classe, in una prospettiva intersezionale (AKOTIRENE, 2019). Questo approccio implica la necessità di discutere la nozione di canone, Reis (1992) e Wollf (1985),

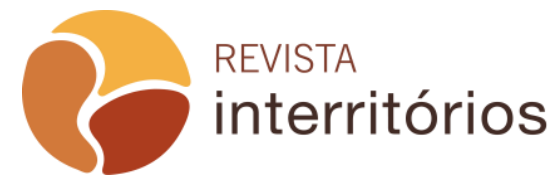

Interritórios | Revista de Educação Universidade Federal de Pernambuco, Caruaru, BRASIL | V.6 N.10 [2020] 
nonché il luogo di intervento, Ribeiro (2017). Come progetto di insegnamento istituzionalizzato, è operativo da luglio 2017 presso I'Istituto Federale di Alagoas, Campus Marechal Deodoro.

Intersezionalità. Formazione di lettori / es. Leggi le donne.

Compreendera que sua vida, um grão de areia lá no fundo do rio, só tomaria corpo, só engrandeceria, se se tornasse matéria argamassa de outras vidas. Descobrira também que não bastava saber ler e assinar o nome. Da leitura era preciso tirar outra sabedoria. Era preciso autorizar o texto da própria vida, assim como era preciso ajudar a construir a história dos seus. E que era preciso continuar decifrando nos vestígios do tempo os sentimentos de tudo que ficara para trás. E perceber que por baixo da assinatura do próprio punho, outras letras e marcas haviam. (CONCEIÇÃO EVARISTO)

\section{De mãos dadas numa ciranda}

Muitos são os desafios que se impõem, na escola, em especial quando pensamos o processo de formação de leitoras e de leitores, a partir de uma perspectiva que desenvolva o senso crítico e aprofunde a consciência de si. Nas palavras de Conceição Evaristo, em Ponciá Vicêncio, um dos livros lidos no clube de leitura cuja experiência é relatada ao longo deste artigo, "[...] não bastava saber ler e assinar o nome. Da leitura era preciso tirar outra sabedoria. Era preciso autorizar o texto da própria vida, assim como era preciso ajudar a construir a história dos seus" (EVARISTO, 2017, p. 109). Toda essa reflexão que a autora nos aponta tem norteado as atividades do Leia Mulheres Marechal Deodoro, no sentido de compreender que o aspecto mais relevante do trabalho de formação de leitoras e leitores é, justamente, permitir que o caminho do aprendizado e da prática da leitura se desenvolva como esse rio no qual todos os grãos de areia se encorpam, tornando-se "argamassa de outras vidas". As águas desse rio, cujo leito é formado pelo conjunto das nossas experiências, da argamassa que nos tornamos quando cada grão de areia se une aos outros, correm num sentido diferente do isolamento que, tradicionalmente, o espaço formal da escola impõe a todas as pessoas que o constituem.

Muitas são as mãos com as quais as nossas se cruzam no espaço da escola: mãos que se abrem ou se fecham, se doam ou se retraem, se tocam ou se evitam. Com todas elas, podemos iniciar uma ciranda, a todas elas podemos 
nos unir. Acreditamos que essa imagem é uma boa metáfora para apresentar o que é a experiência do clube de leitura Leia Mulheres Marechal Deodoro, porque a formação da ciranda pressupõe espontaneidade, vontade de participar, união de vozes e construção coletiva. No entanto, tradicionalmente, esses elementos não caracterizam as práticas pedagógicas com as quais nos deparamos em nosso cotidiano escolar. Nesse sentido, a imagem da ciranda não é comum para pensar tais relações e essa estranheza já é um aspecto a partir do qual se pode pensar esse espaço. Ao reivindicar a imagem da ciranda para apresentar a nossa experiência, reivindicamos também a circularidade e a coletividade que a caracterizam: uma ciranda não se dança em filas, uma ciranda não se dança com mãos que não se tocam, uma ciranda não acontece sem engajamento coletivo.

Numa ciranda, além de darem-se as mãos, as pessoas podem se ver a partir de qualquer ponto da roda. Mão e olho conduzem os movimentos de forma harmoniosa, promovem entrega e partilha, permitem que os pés entrem em sintonia, compartilhem um ritmo, aprendam a dançar no seu próprio tempo sem desrespeitar tempos outros. Juntos, mãos, olhos e pés constroem sentidos, compartilham experiências, abrem espaço para que novos integrantes cheguem à roda, promovem acolhida e permitem a troca de afeto. No centro da ciranda, estão os mais variados livros de autoria feminina, em torno dos quais as ideias giram, as vozes dançam e as experiências de leitura se constroem. A ciranda, enquanto roda de leitura, reordena os espaços de forma mais democrática, menos hierarquizada, sem a centralidade na figura da professora ou do professor. Pensar a necessidade desses elementos no espaço escolar e aliá-los à formação de leitoras e leitores no contexto da educação básica é fundamental para compreender a constituição do clube de leitura Leia Mulheres Marechal Deodoro. Antes disso, no entanto, é preciso resgatar as vozes e as mãos que deram início ao movimento dessa ciranda em um contexto mais amplo.

Um grito que nasceu das vielas escuras da opressão e ecoou nos muros e sobre os muros dos territórios virtuais. Foi de um grito por igualdade de gênero, na perspectiva de libertar do porão as vozes femininas plantadas nas páginas de cada livro, publicado na encruzilhada do patriarcalismo mundial, que surgiu 0 Leia Mulheres. Forte como o som dos gritos por justiça, resistente como o peito que atravessa a encruzilhada do gueto, o projeto Leia Mulheres é, sobretudo, um caminho seguro e afetuoso para fortalecer a escrita de autoria feminina e romper com o silenciamento construído sobre a intelectualidade das mulheres.

No ano de 2014, uma mulher, a escritora e ilustradora britânica Joanna Walsh, lançou pela internet, no Twitter, uma campanha que tinha como principal objetivo incentivar as pessoas a lerem mais livros escritos por mulheres e, assim, dar visibilidade às obras e produções de autoria feminina, bem como "estimular 
o aumento da participação delas na literatura e contribuir para uma reorientação do mercado editorial [...], fundar resistência, viabilizar o debate e ampliar os horizontes dos leitores quanto à produção feminina" (LOUSA; SANTOS, 2016, p. 62-65). Nessa perspectiva, ela lançou a hashtag \#readwomen2014. O movimento criado somente no ambiente virtual espalhou-se rapidamente para o espaço físico, surgindo inúmeros clubes de leitura. A hashtag na versão traduzida para o português, \#LeiaMulheres, foi também adotada no Brasil. Assim, inspiradas na proposta de Walsh, as brasileiras Juliana Leunroth, Juliana Gomes e Michelle Henrique, deram início ao Leia Mulheres em 2015, na capital paulista, onde passaram a se reunir em livrarias e espaços culturais, fundando 0 clube de leitura Leia Mulheres, com o objetivo de ler e discutir exclusivamente livros de autoria feminina, das clássicas às contemporâneas.

Ao darem-se as mãos, as criadoras do clube de leitura Leia Mulheres, em São Paulo, perceberam a possibilidade de ampliar essa roda, abrir espaço e fazer a ciranda do Leia Mulheres circular pelo país inteiro. Hoje, sob a coordenação das criadoras do clube de leitura, o projeto está presente em 158 (cento e cinquenta e oito) cidades, distribuídas entre os 26 (vinte e seis) estados brasileiros e o Distrito Federal, sendo o estado de São Paulo o que possui o maior número de clubes de leitura/ cidades participantes: um total de 41 (quarenta e uma) cidades $^{3}$, atualmente. Por orientação das mediadoras nacionais do projeto, apenas um clube deve ser criado em cada cidade.

Além de promover a circulação, leitura e discussão de livros de autoria feminina, o projeto também promove o protagonismo feminino, por isso apenas mulheres podem ser mediadoras locais dos clubes. Nesse contexto, em cada cidade, os clubes seguem um modelo nacional: encontros mensais, leituras de livros de autoria feminina e presença apenas de mulheres na mediação. Para além disso, cada grupo atua a partir das suas singularidades. Dessa forma, todos os grupos cumprem a agenda mínima de promover um encontro por mês para discutir o texto lido, mas podem desenvolver e protagonizar outras atividades, como acontece em muitas das cidades onde o projeto acontece. Em Alagoas, o Leia Mulheres está presente em 4 (quatro) cidades: Maceió, Marechal Deodoro, Arapiraca e União dos Palmares, com criação em 2015, 2017, 2018 e 2019, respectivamente.

Em Marechal Deodoro, clube de leitura ao qual este trabalho se refere, 0 clube de leitura Leia Mulheres Marechal Deodoro atua desde o dia 25 de julho

\footnotetext{
${ }^{3}$ Para chegar a esses dados, fizemos um levantamento no site oficial do projeto: http: https://leiamulheres.com.br/. Acesso em: $10 \mathrm{fev}$. 2020. No entanto, há mais grupos espalhados pelo Brasil do que o total contabilizado oficialmente no site. Em Alagoas, por exemplo, além dos três clubes mencionados, encontra-se em atividade, desde 2019, o clube de leitura Leia Mulheres União dos Palmares.
}

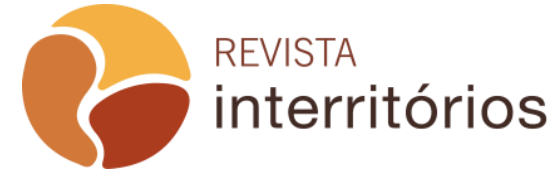

Interritórios | Revista de Educação Universidade Federal de Pernambuco, Caruaru, BRASIL | V.6 N.10 [2020] 
de 2017. A proposição do grupo é uma ação que se iniciou no Campus Marechal Deodoro do Instituto Federal de Alagoas - IFAL, como experiência piloto, em julho de 2017, e durante os anos de 2018 e 2019 foi executada com fomento da Proen/IFAL, Pró-Reitoria de Ensino, por meio de aprovação no Edital № 03/2017/ PROEN/ IFAL e do Edital 11/2018/PROEN/IFAL. Por ocasião do Dia Internacional da Mulher Negra, Latino-Americana e Caribenha e do Dia Nacional de Tereza de Benguela, 25 de julho, realizou-se o primeiro encontro do Leia Mulheres Marechal Deodoro, com a discussão do livro Quarto de despejo, da escritora Maria Carolina de Jesus. A data especialmente escolhida para o início das atividades do grupo testemunha a perspectiva interseccional que norteia a criação e manutenção do clube. A partir dessa obra, questões como a importância do estudo para superar condições de pobreza e miséria, a importância da leitura e da escrita como ato político e as desigualdades de gênero, raça e classe, dentre outros temas, foram discutidas.

A proposição do clube de leitura Leia Mulheres Marechal Deodoro como projeto de ensino institucionalizado no IFAL, Campus Marechal Deodoro, é uma das singularidades do nosso clube. Até a publicação deste artigo, o clube é o único que funciona de forma institucionalizada como projeto de ensino voltado para a formação de leitoras e leitores na educação básica, embora em muitas cidades seja comum os grupos fazerem atividades eventuais em universidades e/ou escolas da rede pública. Além de estudantes, integrantes da comunidade escolar e da comunidade externa ao campus podem participar dos encontros, mas o seu público regular é composto pelo corpo discente da referida instituição.

Diferentemente de outras práticas que se realizam no contexto da escola, em que a obrigatoriedade dá a tônica das ações, o clube de leitura é uma atividade de participação voluntária, sem notas e/ou avaliações, aspectos que voltaremos a abordar mais adiante. Nesse contexto, o clube tem funcionado como uma resposta concreta ao desafio de formar leitoras e leitores na educação básica, a partir da proposição de uma ciranda na qual, ao longo de seus dois anos de existência, o projeto já proporcionou a suas/seus integrantes a experiência de leitura e discussão de trinta livros de autoria feminina, entre obras literárias e não-literárias, até fevereiro de 2020. Algumas dessas leituras subsidiarão teoricamente a construção deste artigo e, além da referência a autoras lidas e discutidas pelo grupo, este relato de experiência dialoga com outras vozes que subsidiam nossa abordagem acerca da autoria feminina e de questões relacionadas ao cânone literário.

\section{Com os pés fincados no chão}


As relações entre autoria feminina e cânone literário podem ser um ponto a partir do qual podemos iniciar o percurso que fundamenta teórica e metodologicamente a proposição e realização do nosso clube de leitura. No contexto específico da educação básica, as aulas de língua portuguesa abordam a literatura e trabalham a leitura a partir do que está institucionalizado no currículo dos cursos cuja construção é pautada pelo cânone literário. Desse modo, a escola, ao tentar cumprir a sua função de formar leitoras e leitores, termina por reproduzir as desigualdades que permeiam o contexto social no qual se insere. Ao adotar uma perspectiva centrada na interseccionalidade, enquanto categoria política e analítica, o clube de leitura Leia Mulheres Marechal Deodoro promove um trabalho de resgate dessas escritoras, considerando que o contexto da autoria feminina precisa ser pensado numa abordagem que, além de considerar as desigualdades de gênero, centra-se também na consideração das relações de raça e classe.

Para abordar esse tema, faz-se necessário, e até urgente, discutir questões relacionadas ao espaço efetivo ocupado pela fruição da leitura no ambiente escolar, bem como à centralidade do cânone literário, no que diz respeito ao ensino de literatura e às práticas de leitura realizadas no espaço da escola. Tais considerações são úteis para que nos aproximemos do modo como as atividades realizadas pelo Leia Mulheres Marechal Deodoro configuram-se como uma resposta concreta ao desafio de formar leitoras e leitores a partir de uma perspectiva interseccional, centrada na leitura de textos de autoria feminina.

Talvez, o primeiro desafio a ser superado, nesse contexto, diga respeito às estratégias de insubmissão ao cânone literário, enquanto instância reguladora que incide diretamente sobre o processo de formação de leitoras e leitores, em especial nas salas de aula do ensino médio. Do ponto de vista histórico e político, a condição da mulher escritora e a constituição do cânone, enquanto princípio de exclusão promotor do apagamento da sua figura no cenário da literatura, estão intrinsicamente ligadas. Para entender essa relação, é preciso considerar que o cânone se configura como uma instituição que promove o silenciamento das mulheres, mas não só delas, uma vez que vários grupos são excluídos de seu domínio. Essa característica é fundamental para a compreensão dos seus mecanismos de atuação, porque desnuda os fatores políticos e ideológicos que estão implicados nele.

Enquanto princípio de seleção e, consequentemente, de exclusão, o conceito de cânone não pode ser pensado sem levar em consideração a questão de poder ao qual se vincula, uma vez que a base da sua constituição se fundamenta na eleição de princípios que são ideologicamente determinados. Essa determinação passa pelo fato de que alguns discursos são revestidos de autoridade e podem, tendo como referencial os seus interesses de raça, gênero 
e classe, dentre outros, estabelecer critérios a partir dos quais, no caso da crítica literária, estabelece-se o que é, ou o que não é, considerado boa literatura.

É possível perceber que uma complexa relação de poder, desenhada a partir de contingências histórica e ideologicamente determinadas, ocupa o centro das normas que regulam o estatuto literário que é, ou não, conferido aos textos. Nesse sentido, os conflitos e as assimetrias que marcam as relações estabelecidas socialmente são transpostos para a eleição dos critérios que repercutem na seleção de textos aos quais as estudantes e os estudantes têm acesso no espaço da escola. Assim, é pertinente afirmar que o cânone ocidental, conforme aponta Reis (1992), é elitista, branco, machista, eurocêntrico e seus critérios de inclusão e/ ou exclusão têm como principal parâmetro essas características. Ainda de acordo com esse autor,

[...] o conceito de cânon implica um princípio de seleção (e exclusão) e, assim, não pode se desvincular da questão do poder: obviamente, os que selecionam (e excluem) estão investidos da autoridade para fazê-lo e o farão de acordo com os seus interesses (isto é: de sua classe, de sua cultura, etc.). Convém atentar ainda para o fato de que o exercício desta autoridade se faz num espaço institucional [...]. (REIS, 1992, p. 70).

A relação de poder que caracteriza os princípios de seleção e exclusão que constituem o cânone, no caso da escola, é reforçada pela professora ou pelo professor. Sua figura está investida/o de autoridade para, a partir do que delimita o cânone, operar uma nova seleção/ exclusão, no sentido de escolher quais textos serão lidos em sala de aula. Nesse contexto, as/os estudantes ocupam uma posição muito passiva, cabe-Ihes apenas o papel de receber as indicações/ imposições de leitura e as realizar nos prazos estabelecidos pela/o docente, uma vez que, na maioria dos casos, a leitura é associada a algum tipo de avaliação. Consequentemente, tais exercícios refletem pouco, ou nada, os desejos das/os estudantes, no que diz respeito à abordagem de temas de seu interesse ou de realidades a partir das quais tenham a oportunidade de refletir acerca das suas próprias experiências de vida em diálogo com os textos lidos.

No que diz respeito à constituição do cânone, é diante desse contexto de relações de poder que provocam o silenciamento e o apagamento da presença das mulheres no mundo da escrita, seja ela ficcional ou não ficcional, que se pode compreender a importância do trabalho de resgate histórico operado pelo movimento feminista, a partir da crítica literária feminista e de outros movimentos, e a necessidade de fazer com que ele ultrapasse os muros da academia e chegue às escolas de educação básica. Nas palavras de Bell Hooks (2019, p. 42),

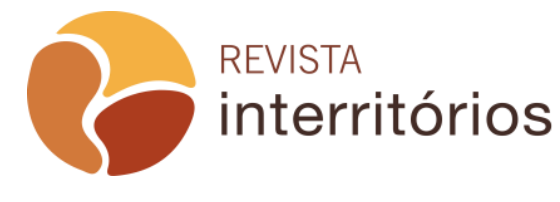

Interritórios | Revista de Educação Universidade Federal de Pernambuco, Caruaru, BRASIL | V.6 N.10 [2020] 


\begin{abstract}
produzir um corpus de literatura feminista junto com a demanda de recuperação da história das mulheres foi uma das mais poderosas e bem-sucedidas intervenções do feminismo contemporâneo. Em todas as esferas da escrita literária e da bibliografia acadêmica, trabalhos produzidos por mulheres haviam recebido pouca ou nenhuma atenção, uma consequência da discriminação de gênero. Notavelmente, quando 0 movimento feminista expôs preconceitos na composição de currículos, muitos desses trabalhos esquecidos e ignorados foram redescobertos.
\end{abstract}

Ao pôr em xeque a suposta neutralidade do cânone literário e da composição do currículo, o feminismo contemporâneo criou possibilidades de compreendermos a partir de quais mecanismos ideológicos essas instâncias operam e, por conseguinte, traçar estratégias de insubmissão e resistência ao seu controle. Conforme enfatiza a autora, esse movimento fortaleceu-se ao entrar na academia, principalmente quando abriu espaço para que as mulheres, em suas pesquisas, falassem de si, por si, e acerca das temáticas que lhes dizem respeito.

Diante desse quadro, os principais desafios que se impuseram à experiência do clube de leitura Leia Mulheres Marechal Deodoro estão postos: como não se submeter aos ditames do currículo e do cânone literário, a fim de promover a formação de leitoras e leitores a partir de uma perspectiva interseccional, centrada na leitura de variados textos escritos por mulheres, com destaque para as mulheres negras? Como promover um movimento em que a necessária teorização torne-se um elemento que alarga a compreensão de mundo de leitoras e leitores, a partir da compreensão de que as opressões de gênero, raça e classe estão interligadas e permeiam o cotidiano de nossas existências?

A tentativa de responder a essas perguntas é atravessada pela compreensão de que a própria prática docente precisa ser despida de seus tradicionais aparatos de controle e poder para que a construção do conhecimento possa se dar numa perspectiva coletiva, não hierarquizada, na qual todas as vozes podem ser ouvidas e participam de forma ativa da construção do conhecimento. Nesse sentido, a criação de um clube de leitura voltado exclusivamente para a circulação de textos de autoria feminina abriu espaço para a possibilidade de colocar as/os estudantes em contato com textos que não chegariam às suas mãos por outros caminhos, além de lhes proporcionar a experiência de protagonizar o seu processo de formação, uma vez que sua autonomia é estimulada no decorrer do processo e as atividades do grupo desenvolvem-se de forma democrática. Trata-se de construir uma 
experiência de leitura cujos passos do caminho são compartilhados por todas as pessoas que integram o clube.

Para discutir o cânone literário, sua construção e o modo como ele é reproduzido na escola, o grupo tomou como ponto de partida a leitura e discussão do livro Um teto todo seu, de Virginia Woolf (1985). A partir desse ensaio, que é referência no âmbito dos estudos de autoria feminina, foi possível discutir questões relacionadas aos aspectos sociais que permeiam o processo de criação literária, além de nos permitir entender como esses aspectos sociais perpassam toda a cadeia de produção, circulação e recepção dos textos escritos por mulheres. Para as estudantes e para os estudantes que compõem o grupo, a discussão do livro de Virginia Woolf trouxe-lhes, pela primeira vez, a possibilidade de pensar nas escritoras como pessoas semelhantes a si, em sua materialidade:

\section{Quais eram as condições em que viviam as mulheres, perguntei- me; pois a ficção, trabalho imaginativo que é, não cai como um seixo no chão, como talvez ocorra com a ciência; a ficção é como uma teia de aranha, muito levemente presa, talvez, mas ainda assim presa à vida pelos quatro cantos. (WOOLF, 1985, p. 55).}

Ao considerar essa pergunta, o grupo abordou a questão da autoria feminina, do acesso à educação formal e da posse "do teto e do dinheiro" como privilégios de alguns grupos em detrimento de outros, ideia que permeia todo o livro. Ao aproximar essa discussão da realidade vivida pelas/os estudantes, foi possível, ainda, perceber que a discussão trazida por Virginia Woolf é fundamental para entender o porquê do nosso projeto e, mais que isso, perceber o porquê da invisibilidade das mulheres escritoras nas aulas regulares de língua portuguesa ofertadas no currículo da instituição. Por outro lado, a abordagem crítica do livro, em diálogo com a experiência de vida das/os estudantes, de acordo com os pressupostos da pedagogia engajada, abriu espaço para a percepção de que questões de raça e classe não são nomeadas ou abordadas no ensaio de Virginia Woolf, mas são fundamentais para a discussão desse processo.

A centralidade que a autora dá à questão de gênero permitiu vislumbrar, inicialmente, o contexto de invisibilidade da mulher escritora, a partir de relações de poder que permeiam o processo de produção, recepção e circulação de livros, tanto no âmbito da ficção quanto da não-ficção. Para isso, foi fundamental discutir o modo como os espaços formais de produção do conhecimento são historicamente masculinos e eurocêntricos. Nessa discussão, Virginia Woolf (1985) aponta-nos a questão de gênero; o aspecto eurocêntrico, diretamente 
ligado ao colonialismo e à branquitude, chegou-nos a partir de outras perspectivas que abordaremos a seguir.

Essa percepção inicial das relações de gênero e a consequente invisibilidade das mulheres escritoras consolidou-se ainda mais a partir da leitura de Simone de Beauvoir (2016), em O segundo sexo. Ao discutir o volume 1, fatos e mitos, o grupo pôde perceber o modo como a categoria de gênero constitui-se e molda as relações sociais nas quais, não só as mulheres escritoras, mas todas/os nós, integrantes do projeto, estamos inseridas/os. Destaca-se, nesse contexto, o modo como a autora parte da discussão da alteridade para formular a noção de gênero e abordar as relações de poder que estão implicadas nessa categoria: "A mulher determina-se e diferencia-se em relação ao homem, e não este em relação a ela; a fêmea é o inessencial perante o essencial. O homem é o Sujeito, o Absoluto; ela é o Outro" (BEAUVOIR, 2016, p. 13). Ao mostrar a unilateralidade do processo que apresenta a mulher como o Outro universal, Simone de Beauvoir descortina as relações de poder, tanto no plano social e político, quanto no simbólico, que estão em disputa nas tentativas de perpetuação das desigualdades de gênero. Assim, a autora afirma:

[Os homens] Ocupam, na indústria, na política, etc., maior número de lugares e os postos mais importantes. Além dos poderes concretos que possuem, revestem-se de um prestígio cuja tradição a educação da criança mantém: o presente envolve o passado, e no passado toda a história foi feita pelos homens. No momento em que as mulheres começam a tomar parte na elaboração do mundo, esse mundo é ainda um mundo que pertence aos homens. (BEAUVOIR, 2016, p.17).

O modo como a educação, historicamente, funciona na perspectiva de manter o status quo foi um ponto destacado, ao longo das nossas discussões, e foi ampliado por algumas leituras que comentaremos a seguir. Por ora, para permanecer na abordagem feita por Simone de Beauvoir, é necessário compreender que, no seu processo de surgimento, o feminismo universalizou a noção de mulher e também a de homem. Os poderes concretos mencionados por Simone de Beauvoir não estão, historicamente, na mão de todos os homens, de maneira uniforme. Assim como mulheres de realidades diferentes vivem dinâmicas de opressão de formas diferentes. A discussão feita a partir das experiências de vida das/os integrantes do grupo permitiu-nos entender que essa perspectiva de gênero universaliza um tipo de homem, um tido de mulher. No entanto, no modo como vivemos e compartilhamos nossas experiências de gênero, é possível perceber que homens e mulheres precisam ser consideradas/os de forma mais ampla, a partir do entrecruzamento dos 
elementos que constituem quem somos e como nos posicionamos no mundo onde vivemos.

As leituras e discussões dos livros Mulheres, raça e classe, de Angela Davis (2016) e O que é lugar de fala?, de Djamila Ribeiro (2017), tornaram-se referências muito importantes para o questionamento dos limites da centralidade da noção de gênero e do processo de universalização das mulheres, operacionalizado no surgimento do movimento feminista. A esse respeito, Djamila Ribeiro (2017, p. 21) afirma:

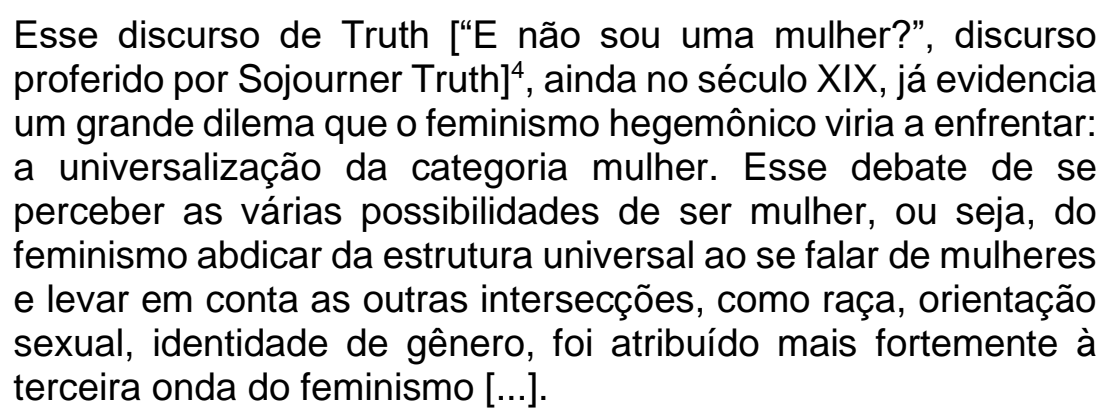

A partir das considerações de Djamila Ribeiro, o grupo percebeu que a diversidade de experiências que atravessam a realidade de seus componentes exige um aparato que seja coerente com essa diversidade e não reitere as opressões contra as quais nos posicionamos. Nesse sentido, o projeto discute textos de autoria feminina, mas não elege gênero como única categoria de análise a partir da qual os textos são discutidos no sentido de aproximá-los das vivências das/os estudantes. Essa postura justifica-se quando se considera os objetivos do projeto, que passam pela construção de vozes autônomas, capazes de dialogar de forma crítica com os textos lidos e os relacionar à análise do contexto em que vivem. A construção da autonomia dessas vozes precisa considerar que elas são plurais, têm interesses e experiências diversas e encontram no grupo um caminho de afirmar suas singularidades e terem suas vivências respeitadas.

Nesse contexto, é oportuna e necessária sua abordagem acerca da construção do conhecimento a partir do privilégio social e dos pilares eurocêntricos. Ao contextualizar a produção intelectual de Lélia Gonzalez, Djamila Ribeiro (2017, p. 24-25) demonstra que ela

[...] criticava a hierarquização de saberes como produto da classificação racial. Ou seja, reconhecendo a equação: quem

\footnotetext{
4 TRUTH, Sojourner. E não sou uma mulher?. Disponível em: https://www.geledes.org.br/enao-sou-uma-mulher-sojourner-truth/. Acesso em: 10 fev. 2020.
} 
possui privilégio social possui o privilégio epistêmico, uma vez que o modelo valorizado e universal da ciência é branco. A consequência dessa hierarquização legitimou como superior a explicação epistemológica eurocêntrica conferindo ao pensamento moderno ocidental a exclusividade do que seria conhecimento válido, estruturando-o como dominante e, assim, inviabilizando outras experiências do conhecimento.

Por caminhos diferentes, as obras de Djamila Ribeiro (2017) e Angela Davis (2016) permitiram ao grupo a possibilidade de realizar discussões que são pouco comuns, ou raras, no contexto da sala de aula da educação básica: refletir sobre a importância da educação e as relações de poder que permeiam não só o acesso à educação, mas também o modo como o conhecimento é construído e difundido. A partir dessas discussões, as/os estudantes que integram o clube de leitura puderam compartilhar experiências acerca do modo como enxergam o lugar onde estudam, do conhecimento ao qual têm acesso e da importância de lutar pela garantia da educação pública, gratuita, de qualidade para si e para outras gerações.

A discussão de Mulheres, raça e classe (DAVIS, 2016) permitiu aprofundar essas questões, ao demonstrar como as categorias de gênero, raça e classe estão interligadas, formando uma cadeia de opressão que recai, de forma mais incisiva, sobre as mulheres negras. Ao demonstrar que "o racismo funciona de modo intrincado" Angela Davis (2016, p.101) aborda as correlações entre as desigualdades de gênero, raça e classe, sendo, portanto, inseparáveis os elos que ligam uma forma de opressão à outra. Não cabe, pois, nesse contexto, a postura de hierarquizar categorias e/ou opressões. Esse argumento permeia a construção de Mulheres, raça e classe, obra de Angela Davis (2016) lida pelo clube de leitura, e é retomado pela autora em As mulheres negras na construção de uma nova utopia:

É preciso compreender que classe informa a raça. Mas raça, também, informa a classe. E gênero informa a classe. Raça é a maneira como a classe é vivida. Da mesma forma que gênero é a maneira como a raça é vivida. A gente precisa refletir bastante para perceber as intersecções entre raça, classe e gênero, de forma a perceber que entre essas categorias existem relações que são mútuas e outras que são cruzadas. Ninguém pode assumir a primazia de uma categoria sobre as outras. (DAVIS, 2011, s/p).

Outro ponto fundamental é a abordagem que a autora faz das relações entre acesso à educação e luta pela liberdade. Ao citar Frederick Douglass, quando este afirma que "o conhecimento torna uma criança inadequada para a escravidão" (apud DAVIS, 2016, p. 108), a autora enfatiza a relação entre 
educação e liberdade, como aponta o título de um dos capítulos do seu livro, e nos demonstra que o acesso à educação é a principal e mais eficaz forma de lutar pela liberdade e contra as diversas formas de opressão. Essa relação entre educação e liberdade permeia não só o modo como discutimos o contexto da educação, mas também o modo como se delineia a metodologia usada nos encontros.

Há, nos encontros do clube de leitura, uma prática que se pauta pelo exercício cuidadoso da escuta e pelo reconhecimento de que o espaço formal da escola não pode subtrair das/os estudantes os saberes e as experiências que são trazidas das suas comunidades. A subtração desse tipo de conhecimento, muitas vezes, passa pela reprodução de discursos hegemônicos de acordo com os quais apenas um tipo de saber tem validade: o acadêmico. Historicamente, esse saber acadêmico tem gênero, cor e classe, como bem demonstraram as autoras lidas e comentadas aqui.

Como dito anteriormente, a participação no clube de leitura acontece de forma voluntária. Consequentemente, não há a imposição de avaliação ou atribuição de notas ao final de cada leitura. No entanto, não é só nesse aspecto que os encontros do clube se distanciam das aulas regulares: a mediação dos encontros é compartilhada pela professora proponente do projeto de ensino e outras estudantes que o integram e tem a função de garantir que o espaço do encontro seja um ambiente no qual as pessoas falem sem ser interrompidas e se sintam confortáveis para, a partir da leitura, compartilhar não só a sua compreensão do texto, mas também a sua experiência de vida.

A partir da criação de um espaço seguro para discutir e escolher os textos lidos, é a voz das estudantes e dos estudantes que passa a ser autônoma, numa perspectiva em que se pode prescindir dos significados prontos, trazidos por professoras e professores, ou pelo material didático, para significar a leitura e a vida a partir da experiência de cada integrante do clube. A partir da perspectiva metodológica da pedagogia engajada, acreditamos, a partir das palavras de Bell Hooks (2017, p. 271), que

a lição importante que aprendemos juntos, a lição que nos permite caminhar juntos dentro e fora da sala de aula, é a do engajamento mútuo. [...] Quando ensino, encorajo-os a criticar, avaliar e fazer sugestões e intervenções à medida que avançamos. Quando os alunos [e as alunas] se veem mutuamente responsáveis pelo desenvolvimento de uma comunidade de aprendizado, oferecem contribuições construtivas. 
A partir do engajamento mútuo e da percepção do grupo como um espaço em que todas as vozes são encorajadas, todas as perspectivas são ouvidas e respeitadas, o Leia Mulheres Marechal Deodoro tem se consolidado, ao longo da sua trajetória, como uma "comunidade de aprendizado" (HOOKS, 2017) que valoriza suas/seus componentes em suas particularidades. A pluralidade de experiências, de narrativas, de vozes é uma das principais características do nosso clube de leitura, enquanto comunidade de aprendizado. $O$ ato de ouvir a consideração de cada integrante acerca do livro lido e da experiência do encontro é um ato político, que combate estruturas promotoras do silenciamento dos indivíduos, sobretudo dos que pertencem a grupos minoritários, e permite pensarmos a educação numa perspectiva que não reproduz as desigualdades/opressões contra as quais lutamos. Ainda na perspectiva de Bell Hooks (2017, p. 114-115),

o ato de ouvir coletivamente uns aos outros afirma o valor e a unicidade de cada voz. Esse exercício ressalta a experiência sem privilegiar as vozes dos alunos [e das alunas] de um grupo qualquer. Ajuda a criar uma consciência comunitária da diversidade das nossas experiências e proporciona uma certa noção daquelas experiências que podem informar o modo como pensamos e o que dizemos. [...] os alunos [e as alunas] em geral não sentem a necessidade de competir, pois o conceito de voz privilegiada da autoridade é desconstruído pela nossa prática crítica coletiva.

Distanciar-se do "conceito de voz privilegiada da autoridade" é uma construção que se percebe entre as/os integrantes do Leia Mulheres Marechal Deodoro, inclusive, nas atividades que se voltam para todo o público da escola. Além dos encontros mensais, são realizados debates, mesas-redondas, encontros com escritoras, oficinas, debate de filmes, dentre outras atividades. Nessas ocasiões, as/os integrantes do clube de leitura apresentam maior desenvoltura para falar em público, demonstrar suas opiniões e compreensões de suas leituras, mesmo quando estão diante de pessoas que poderiam ser lidas como vozes privilegiadas de autoridade.

Essa perspectiva metodológica dialoga diretamente com a perspectiva teórica que fundamenta a prática do nosso clube de leitura, uma vez que uma abordagem que coloca a interseccionalidade no centro do processo de formação de leitoras e leitores, em primeiro lugar, impõe a tarefa de (re)pensar a prática docente, a partir de paradigmas que a reconfigure para além da criação e exercício de mecanismos de controle e poder. Essa necessidade justifica-se a partir da compreensão de que a interseccionalidade, enquanto categoria analítica e política, está pautada em uma perspectiva que se desenvolve na contramão de abordagens em que pesam as

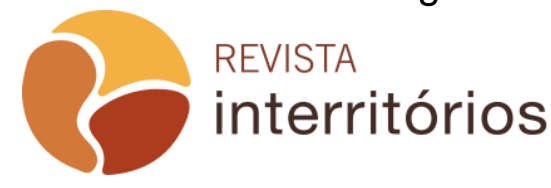

Interritórios | Revista de Educação Universidade Federal de Pernambuco, Caruaru, BRASIL | V.6 N.10 [2020] 
hierarquias que supervalorizam a teoria em detrimento da prática, bem como as que supervalorizam uma forma de opressão em detrimento de outra/s.

Na perspectiva de Carla Akotirene (2019, p. 19), "a interseccionalidade visa dar instrumentalidade teórico-metodológica à inseparabilidade estrutural do racismo, capitalismo e cisheteropatriarcado". Ao referir-se ao modo como essas categorias relacionam-se de forma indissociável, a autora enfatiza que essa abordagem impossibilita a consideração dessas opressões em um sistema hierárquico, em que um dos sistemas pode ser supervalorizado, do ponto de vista analítico, ou político, em detrimento dos outros. Além da suposta hierarquia entre sistemas de opressão que, na verdade, alimentam-se mutuamente, a perspectiva interseccional também abole hierarquias que supervalorizam a teoria, em detrimento da prática, bem como aquelas em que o conhecimento formal/ acadêmico sobrepõe-se à experiência de vida de cada pessoa.

Ao pensar a formação de leitoras e leitores a partir de uma perspectiva interseccional, o clube de leitura Leia Mulheres Marechal Deodoro compreende que a escola é um espaço marcado pela complexidade das relações que constituem o espaço onde ela se localiza. A escola é um microcosmo que reflete a diversidade das relações sociais onde está inserida e precisa trabalhar para que as desigualdades de gênero, raça e classe sejam compreendidas, discutidas, combatidas e, sobretudo, não se reproduzam dentro do ambiente escolar.

Nesse contexto, é possível perceber que assimetrias podem ser incorporadas de diversas formas tanto ao ambiente escolar quanto à tessitura do texto, uma vez que tanto a escola quanto os textos são construções históricas da sociedade na qual se inserem. É nessa perspectiva que as leituras realizadas nesses dois anos e meio de projeto provocam reflexões acerca das desigualdades que marcam a sociedade brasileira, em especial a alagoana, a partir de dois aspectos que se comunicam: 1) a consideração das desigualdades de gênero, raça e classe e a necessidade de combatê-las; 2) a consideração de que essas desigualdades repercutem de forma direta no cenário da produção literária de autoria feminina, conforme se demonstrará mais a diante, bem como no imaginário de homens e mulheres, meninos e meninas que são expostos/as a ela cotidianamente.

No contexto dessas desigualdades, a criação do clube de leitura apresenta uma estratégia voltada à permanência e êxito das/os estudantes na escola, por desenvolver ações contínuas que ajudam a construir o desenvolvimento do hábito da leitura e conduzem à superação das dificuldades de leitura e interpretação textual que, muitas vezes, as alunas e os alunos carregam como marca negativa da educação deficitária que Ihes foi oferecida em etapas anteriores da sua formação. Para 
além dessa finalidade, o clube de leitura também funciona como um espaço a partir do qual as estudantes e os estudantes podem construir relações de apoio e solidariedade que contribuem para a sua permanência no contexto escolar.

As discussões acerca das relações de gênero, raça e classe, desenvolvem-se no sentido de possibilitar a compreensão, inclusive, dos fatores sociais que estão imbrincados na noção de êxito escolar. As leituras, dentre outras possibilidades, criam espaço para a compreensão de que uma possibilidade de permanência exitosa na escola não pode ser lida a partir da análise fria de notas, ou desempenho individual de cada estudante. $O$ direito à educação pública, gratuita e de qualidade, as desigualdades que impactam a vida de cada estudante e se desdobram na escola, todos esses fatores passaram a ser vistos, ao longo da existência do grupo, como elementos estruturais que perpassam a existência de cada membro da comunidade escolar e influenciam diretamente os aspectos relacionados à permanência e ao êxito escolar.

\section{E a cabeça voltada para os livros}

Além dos encontros mensais, o clube de leitura Leia Mulheres Marechal Deodoro realiza debates, mesas-redondas, encontros com escritoras, oficinas, debate de filmes, dentre outras atividades. Nessas ocasiões, as/os integrantes do clube de leitura apresentam maior desenvoltura para falar em público, demonstrar suas opiniões e compreensões de suas leituras, mesmo quando estão diante de pessoas que poderiam ser lidas como vozes privilegiadas de autoridade. Destacam-se, nesse contexto, os momentos em que as alunas e os alunos participaram de encontros promovidos pelo Leia Mulheres Marechal Deodoro com as autoras de livros lidos pelo grupo: as gaúchas Angélica Freitas ${ }^{5}$ e Luísa Geisler, a cearense Tercia Montenegro ${ }^{6}$ e a alagoana Arriete Vilela.

\footnotetext{
${ }^{5}$ Em dezembro de 2018, o clube de leitura Leia Mulheres Marechal Deodoro contribuiu com o trabalho da curadoria da Flimar, Feira Literária de Marechal Deodoro, numa edição especial, voltada exclusivamente para o protagonismo feminino, com o tema "Sou Literatura, sou cultura, sou mulher". Na ocasião, a escritora Angélica Freitas foi uma das escritoras convidadas para o evento. Gentilmente, a poeta aceitou nosso convite para um bate-papo com as/os integrantes do grupo e demais estudantes no auditório do Campus Marechal Deodoro. Embora isso não estivesse previsto, as alunas e os alunos realizaram uma sessão de leitura de poemas para a autora.

${ }^{6}$ Em agosto de 2019, o Circuito Arte da Palavra, promovido pelo Sesc Alagoas, trouxe para o nosso estado as escritoras Luísa Geisler e Tercia Montenegro. Como parte integrante das atividades do evento, as autoras convidadas participaram de uma roda de conversa com estudantes de uma escola pública a ser definida pelo Sesc. Nessa ocasião, o Leia Mulheres Marechal Deodoro foi contemplado com a presença das escritoras para discussão de seus
}

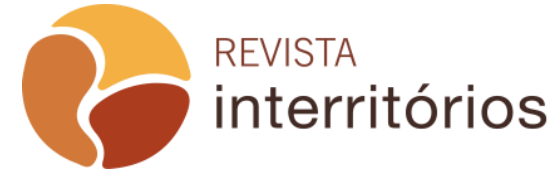

Interritórios | Revista de Educação Universidade Federal de Pernambuco, Caruaru, BRASIL | V.6 N.10 [2020] 
Os encontros com as escritoras, de diversas formas, constituem-se como experiências enriquecedoras para todas/os nós. Além de promover a circulação de textos de autoria feminina, o clube de leitura, ao questionar os limites do cânone, possibilita a aproximação das leitoras e dos leitores com as escritoras contemporâneas, como é o caso das escritoras mencionadas. Uma das riquezas desses encontros reside na possibilidade de perceber as escritoras numa perspectiva que as aproxima das alunas e dos alunos e, ao aproximá-las/os, abre a possibilidade para que as leitoras e os leitores passem a se perceber como pessoas que também podem ocupar esse lugar de autoria. Tanto o contato com as escritoras de outros estados, quanto o encontro com as escritoras alagoanas foram ricos nesse sentido.

Em especial, a mesa "Palavra de mulher fora do livro: a poesia que vem da periferia", com as poetas negras Ísis Florescer, Karol Moraes e Mary Alves, realizada pelo grupo durante a $9^{a}$ Bienal Internacional do Livro de Alagoas, promovida pela Editora da Universidade Federal de Alagoas, cumpriu uma função muito importante no sentido de aproximar as leitoras e os leitores não só das escritoras, mas também da possibilidade de ocupar o espaço da autoria. A mesa foi uma proposição e realização do grupo no estande da Biblioteca Estadual Graciliano Ramos. A realização da mesa também pode ser lida como uma resposta a dois fatos recentes: no ano de 2019, o principal edital de publicação de obras literárias do estado, promovido pela Imprensa Oficial Graciliano Ramos e financiado pelo governo do estado, contemplou a publicação de seis obras literárias, dentre 124 inscrições, conforme dados divulgados nas mídias oficiais do governo do estado ${ }^{7}$. Nenhuma delas é de autoria feminina ${ }^{8}$.

Também em 2019, a curadoria da 9a Bienal Internacional do Livro de Alagoas, por meio da Edufal, promoveu a edição mais inclusiva e acessível do evento ao longo de suas nove edições, levando-o, pela primeira vez, para as ruas de um bairro histórico da capital alagoana, fato que merece nosso reconhecimento. No entanto, nenhuma das mesas propostas pela curadoria, em sua programação principal, abriu espaço para a presença de representantes de

contos. Mais uma vez, o encontro foi realizado no auditório do campus para que todas/os as/os estudantes da instituição pudessem ouvir as escritoras e conversar com elas.

${ }^{7}$ MONTEIRO, Patrycia. Imprensa Oficial anuncia vencedores do Edital para Publicação de Obras Literárias, disponível em: http://agenciaalagoas.al.gov.br/noticia/item/30605-imprensaoficial-anuncia-vencedores-do-edital-para-publicacao-de-obras-literarias. Acesso em: 10 fev. 2020.

8 Em 2017, uma das autoras deste artigo realizou uma pesquisa PIBIC, financiada com bolsa para duas alunas por um edital da Pró-Reitoria de Pesquisa e Inovação do Ifal, acerca da produção literária de autoria feminina contemporânea em Alagoas. Os dados encontrados no decorrer dessa pesquisa foram apresentados durante a 9a Bienal Internacional do Livro de Alagoas e apontam que a ausência de mulheres contempladas no referido edital é uma constante, com exceção do ano 2018.

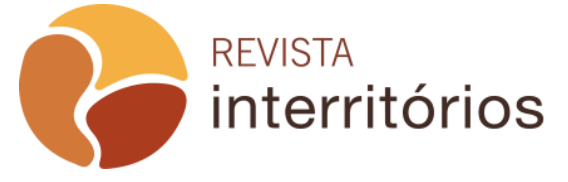

Interritórios | Revista de Educação Universidade Federal de Pernambuco, Caruaru, BRASIL | V.6 N.10 [2020] 
Alagoas. Diante dessas ausências, reunimos as poetas mencionadas, num encontro potente que, dentre outras possibilidades, mostrou ao público que, na ausência do livro e do espaço na programação oficial, a poesia sempre encontrará outras formas para circular.

Ainda nesse contexto de pensar-se enquanto alguém que pode e deve ocupar o lugar da autoria, as/os integrantes do clube de leitura e outras/os estudantes da instituição puderam participar de duas oficinas ofertadas pelo Leia Mulheres Marechal Deodoro. A primeira delas, realizada em outubro de 2018, foi a Oficina para formação de leitoras com modalidade rua e espaços abertos. Trata-se de uma atividade realizada pela Ong Ateliê Ambrosina, que promove espaço de discussão e promoção do protagonismo feminino a partir de várias linguagens artísticas no Pontal da Barra, em Maceió. Dentre outras atividades, a ong atua na realização do Slam das Minas Alagoas e promove a formação de slamers para participar do evento. Em parceria com o Sesc Alagoas, no Circuito Arte da Palavra, as integrantes do Ateliê Ambrosina promoveram uma oficina voltada exclusivamente para mulheres, integrantes do clube de leitura e outras alunas da instituição, que puderam produzir poesia a partir das suas vivências pessoais e da percepção de como são atravessadas pelas desigualdades de gênero, raça e classe. Uma das participantes dessa oficina, depois dessa experiência, passou a engajar-se na participação e promoção de batalhas de rima que promovem o protagonismo feminino e denunciam a misoginia em algumas batalhas que são realizadas no estado. Ainda nesse contexto de proporcionar às/aos estudantes a possibilidade de vivenciar a experiência da autoria, o Leia Mulheres Marechal Deodoro promoveu, em 2019, a Oficina de Artes Visuais Elas Pintam o Sete, com a presença da poeta e artista visual Lisley Nogueira, que compartilhou com estudantes do campus técnicas de desenho e aquarela.

O Leia Mulheres Marechal Deodoro pôde experimentar várias primeiras vezes com suas/seus integrantes e demais estudantes do campus: o primeiro contato com escritoras que, antes, eram apenas nomes sem materialidade na capa dos livros; a primeira experiência de escrever uma poesia e reconhecer-se nesse lugar da autoria; a primeira ida ao cinema; a primeira ida a uma bienal; a primeira participação em debates de gênero, raça e classe. Essas são algumas das atividades realizadas pelo clube de leitura, que se desdobram e alcançam um público maior dentro da escola. Para além dos encontros mensais, levar as discussões para toda a comunidade escolar é uma preocupação constante do nosso projeto e isso tem sido realizado com o apoio da gestão da instituição, de servidoras e servidores do campus e, sobretudo, com o engajamento das pessoas que fazem parte do Leia Mulheres Marechal Deodoro. 
A experiência do Leia Mulheres Marechal Deodoro mostrou que é possível formar leitoras e leitores, no contexto da educação básica, a partir da circulação de textos de autoria feminina. Ao adotar a perspectiva metodológica da pedagogia engajada, ao longo dos seus dois anos e meio de existência, o projeto mostrou que é possível tocar alunas e alunos para além dos muros da escola, no sentido de permitir a construção de um olhar que se volta para a análise da realidade de forma crítica, e construir uma comunidade de aprendizado em que professoras e alunas/os compartilham as alegrias do conhecimento à medida em que aprendem e ensinam mutuamente. Por fim, registra-se o agradecimento especial às mediadoras do projeto e às alunas e alunos que fazem, ou fizeram, parte dessa história de luta, resistência e alegria.

\section{REFERÊNCIAS}

AKOTIRENE, Carla. Interseccionalidade. São Paulo: Sueli Carneiro; Pólen, 2019.

BEAUVOIR, Simone de. O segundo sexo: fatos e mitos. Tradução de Sérgio Milliet. 3. ed. Rio de Janeiro: Nova Fronteira, 2016.

DAVIS, Angela. Mulheres, raça e classe. Tradução Heci Regina Candiane. São Paulo: Boitempo, 2016.

DAVIS, Angela. As mulheres negras na construção de uma nova utopia. Disponível em: https://www.geledes.org.br/as-mulheres-negras-na-construcao-de-uma-novautopia-angela-davis/. Acesso em: 10 fev. 2020.

EVARISTO, Conceição. Ponciá Vicêncio. Rio de Janeiro: Pallas 2017.

HOOKS, Bell. Ensinando a transgredir: a educação como prática da liberdade. Tradução de Marcelo Brandão Cipolla. 2. ed. São Paulo: Editora WMF, Martins Fontes, 2017.

HOOKS, Bell. O feminismo é para todo mundo: políticas arrebatadoras. Tradução de Ana Luiza Libânio. 5. ed. Rio de Janeiro: Rosa dos Tempos, 2019.

LOUSA, Pilar Lago; SANTOS, Maria Clara Dunck. Leia Mulheres: literatura, empoderamento e divulgação da autoria feminina em Goiânia. Revista EM TESE, Belo Horizonte, v. 22, n.3, p.62-77, set-dez. 2016.

MONTEIRO, Patrycia. Imprensa Oficial anuncia vencedores do Edital Para Publicação de Obras Literárias. Disponível em: http://agenciaalagoas.al.gov.br/noticia/item/30605imprensa-oficial-anuncia-vencedores-do-edital-para-publicacao-de-obras-literarias. Acesso em: 10 fev. 2020.

REIS, R. Cânon. In: JOBIM, J. L. (org.) Palavras da crítica: tendências e conceitos no estudo da literatura. Rio de Janeiro: Imago, 1992. p. 65-92. 
RIBEIRO, Djamila. O que é lugar de fala?. Belo Horizonte: Letramento, 2017.

TRUTH, Sojourner. E não sou uma mulher?. Disponível em:

https://www.geledes.org.br/e-nao-sou-uma-mulher-sojourner-truth/. Acesso em: 10 fev. 2020.

WOOLF, Virginia. Um teto todo seu. Tradução de Vera Ribeiro. Rio de Janeiro: Nova Fronteira, 1985. 